\title{
Chapter 35 \\ Number Sense in Elementary School \\ Children: The Uses and Meanings Given \\ to Numbers in Different Investigative \\ Situations
}

\author{
Alina Galvão Spinillo
}

\begin{abstract}
This research investigated number sense in second grade Brazilian children (7-8 years old) from different social backgrounds. Study 1 (interview) aimed to identify the general uses given to numbers by children in everyday life situations. Study 2 (multiple choice tasks) examined how children assign meaning to numbers by asking the participants to make judgments about numerical situations involving both numbers and measurement and to provide justifications for their responses. The uses given to numbers in Study 1 were classified into different types: school uses, outside school uses, intellectual abilities and professional uses. The data in Study 2 were analysed according to correct responses and the types of justifications given. Both studies showed that there are some differences between children from different social backgrounds. On the whole, the children presented number sense that needs to be taken into account in the school setting.
\end{abstract}

Keywords Number sense - Children - Social backgrounds · Uses and meaning of numbers

Numbers and quantities, in a broad sense, are part of our daily life, from childhood to adulthood, in the most diverse contexts: at home, on the streets, at school and at work. They are part of the activities we carry out and the plans and the decisions we make. We are surrounded by numbers, and in order to function properly and efficiently in this environment we need to be numerate.

Being numerate involves familiarity with the world of numbers: to be able to think quantitatively in a variety of situations, to be able to employ efficient systems of representation and to understand the logical rules that govern the mathematical concepts inserted in these situations (Nunes and Bryant 1996). Being numerate is related to what in the literature is called number sense.

\footnotetext{
A. G. Spinillo ( $\square)$

Federal University of Pernambuco, Recife, Brazil

e-mail: alinaspinillo@hotmail.com

(C) The Author(s) 2018

G. Kaiser et al. (eds.), Invited Lectures from the 13th International Congress

on Mathematical Education, ICME-13 Monographs,

https://doi.org/10.1007/978-3-319-72170-5_35
} 
One may say that number sense is a cognitive ability that allows individuals to interact successfully with the various resources that the environment provides so that they can generate appropriate solutions to deal with daily activities that involve the use of mathematics. According to several authors (Cebola 2007; Greenes et al. 1993; Greeno 1991; Reys 1989), number sense can be defined as good intuition about numbers, their uses, meanings and relationships, which allows the individual to handle, in an efficient and flexible manner, situations which involve numbers and quantities. It is a skill that develops gradually from knowledge about the properties and meanings of numbers in varied contexts and from the construction of relationships that are not restricted to the use of algorithms.

Reys (1989) defines number sense as an understanding of numbers and operations that allows the application of appropriate resolution strategies and the processing of information, interpreting and communicating it accordingly. Similarly, Greenes et al. (1993) stress that number sense is the capacity for understanding the mathematical relationships involved in problem situations. Godino et al. (2009) and McIntosh et al. (1992) stress that this understanding needs to be flexible, given that the same strategies do not apply to all situations.

Faced with such a broad definition, it is important to be able to identify, both from a psychological and an educational point of view, what the indicators of number sense would be.

Spinillo (2006), based on an analysis of the literature on the subject (e.g., Greeno 1991; Yang et al. 2004), points out some indicators of numerical sense with the objective of contributing to a conceptual understanding of this topic and the creation of educational alternatives that will effectively make students numerate. Without intending to exhaust all possibilities of manifestation of a numerical sense, the author presents and exemplifies several indicators: estimating; performing flexible numerical computation; making quantitative judgments; establishing inferences; using anchors; recognising the plausibility of a result; recognising the absolute and relative magnitude of numbers; understanding the effect of operations on numbers; being able to use and recognise that one instrument or representation medium may be more useful or appropriate than another; and being able to recognise uses, meanings and functions of numbers in different situations.

Flexible numerical computation, mental calculations and estimates, assessed using oral problem-solving tasks, have been the most frequently investigated indicators (Yang 2003; Yang et al. 2004). Spinillo and colleagues, by means of judgment tasks, have investigated the effect of operations on numbers (Spinillo 2011); situations involving measurements (Spinillo and Batista 2009); and the meanings, uses and functions of numbers in different situations (Ribeiro and Spinillo 2006).

The understanding of the meanings and uses numbers can have in everyday life has been highlighted in curricular proposals (NCTM 1989) and by researchers. Cebola (2007), for example, states that children gradually discover what numbers are for and gradually begin to understand that numbers are what allow us to count, order or name something. Children realise that it is through numbers that one can (i) indicate the number of elements in a set (number as cardinal), (ii) say in which 
position an athlete has arrived in relation to other athletes (number as ordinal) and (iii) refer to a car number plate (number as nominal). According to the author, when thinking about numbers and when using them, children broaden their numerical sense. The present paper discusses, based on data obtained in two different studies, the meanings and uses that children assign to numbers in their daily life.

Like any other mathematical knowledge, number sense has its origin in everyday activities performed in the most different social contexts: at home (Blevins-Knabe and Musun-Miller 1996; Clements and Sarama 2007; Siegler 2009), at school (Brocardo and Serrazina 2008; Cebola 2007; Jordan et al. 2009) and on the streets and in the workplace (Nunes et al. 1993; Gainsburg 2005). In terms of socio-economic levels, Clements and Sarama (2007) observed that middle-class parents engage more frequently in mathematical activities with their children than low-income parents. According to Siegler (2009), children from low-income families have experiences which are less favourable to the development of number sense, and begin school with a limited knowledge of mathematics. For Nunes et al. (1993), who have studied low-income children and adolescents who carry out selling and buying activities on the streets, these children present a well-developed mathematical knowledge, although they adopt ways of reasoning different from those valued at school.

On the whole, these studies show that children from different social classes have different mathematical experiences in their daily lives that generate distinct types of mathematical knowledge (not necessarily better or worse). Thus, it seems relevant to examine whether children from different social classes would differ in their ability to intuitively understand numbers and operations. This is the issue addressed in this paper.

Given the large variety of number-sense indicators, the present study focuses specifically on one of these indicators: the uses and meanings assigned to numbers. The purpose of this paper is to discuss the results derived from two different investigative situations. In both studies, the participants are low-income and middle-class Brazilian children (7-8 years old), attending the second grade of elementary school in the city of Recife, Pernambuco, Brazil. None of the participants was engaged in any type of informal commercial activity. ${ }^{1}$

\footnotetext{
${ }^{1}$ It is important to mention that children from low-income families whose parents work as street vendors usually help them with their informal commercial transactions, such as selling snack foods (popcorn, popsicles, sweets, cupcakes etc.) and seasonal fruits. For more details about these informal commercial activities see Carraher et al. (1985) and Saxe (1991). The study conducted by Saxe also describes the four-phase cyclical structure of this practice.
} 


\subsection{Study 1}

Study 1 consisted of clinical interviews whose objective was to identify the general uses given to numbers by children in everyday life situations. Three key questions were presented to each child: (1) What are numbers for? (2) What are sums for? and (3) Why do we measure things? These questions are associated with three fields of mathematical knowledge considered relevant in the national curricular proposal for elementary school in Brazil: numbers, arithmetic operations and measures (MEC/ SEF 1997).

Forty children, 20 from a low-income background and 20 from a middle-class background, took part in the interviews. Each interview was recorded and the responses given were analysed and classified into different types according to the use given to numbers, to operations and to the activity of measuring. The responses were classified by two independent judges between whom the reliability of coding assessment was $82.5 \%$. The cases of disagreement were evaluated by a third independent judge and the final classification was determined by agreement between two of the three judges. The types of responses are described and exemplified below:

Type 1 (school uses): Children provide answers in which they give school-related uses to numbers, operations and measurements. ${ }^{2}$

What are numbers for?

'To do the homework'.

'To have good grades at school'.

What are sums for?

'To learn what is on the board, in the book, in the notebook'.

Why do we measure things?

'So that we know the size of something if the teacher asks'.

Type 2 (outside-school uses): Children provide answers in which they relate numbers, operations and measurements to everyday situations:

What are numbers for?

'So that we know how many biscuits there are in a packet, for example'.

What are sums for?

'To know the total, to count money, to pay the electricity and the water bill'.

'So that we always get the right change'.

\footnotetext{
${ }^{2}$ None of the answers given have included more than one type of usage.
} 
Why do we measure things?

'To know how tall someone is. I am taller than my sister'.

'To know how big a wardrobe is and see if it can go through the door'.

Type 3 (professional uses): Children provide answers in which they relate numbers, operations and measurements to professional activities:

What are numbers for?

'We need to know how to add, subtract. If we want to work, we need to study a lot'. What are sums for?

'To find a job when we grow up'.

'To have a good salary in the future'.

Why do we measure things?

'Because I want to be a dressmaker when I grow up, and I'll have to measure things'.

'To be a good engineer. To build something like a house'.

Type 4 (intellectual abilities): Children provide answers in which they associate numbers, operations and measurement activities with intellectual success/ achievements:

What are numbers for?

'To be clever'.

What are sums for?

'Because if we don't know how to add, to subtract, we are stupid'.

Why do we measure things?

'To learn things'.

'To know more'.

As it can be seen in Table 35.1, and revealed by the Mann-Whitney $U$ test, middle-class children assigned outside-school uses to numbers more often than low-income children did ( $U=8, p=0.0290)$, while low-income children assigned

Table 35.1 Percentage of types of responses in each group

\begin{tabular}{l|l|l}
\hline & Low-income $(n=60)$ & Middle-class $(n=60)$ \\
\hline School uses & 46.7 & 40 \\
\hline Outside school uses & 30 & 43.4 \\
\hline Professional uses & 13.3 & 5 \\
\hline Intellectual abilities & 10 & 11.6 \\
\hline
\end{tabular}


professional uses to numbers more often than middle-class children did ( $U=106$, $p=0.0078)$.

For low-income children, school uses were more frequent than other uses (Friedman test: $X=15.529, p=0.001$ ), whereas for middle-class children, school uses and outside-school uses were approximately the same and more frequent than the other uses (Friedman Test: $X=11.571, p=0.003$ ). It is important to mention that future uses related to professional activities were rarely observed among middle-class children (only 5\%).

Relating these uses to the three fields of mathematical knowledge investigated (numbers, operations and measures), it was observed that, according to the participants:

(1) Numbers were assigned school uses primarily associated with performing arithmetic operations ('Numbers serve to solve the problems in the book, don't they?'). There were no uses or meanings related to the ordering or naming of things, which, according to Cebola (2007), are relevant aspects. When assigned outside-school uses, numbers were associated with counting situations ('They serve to count the things we have. To know how many things we have.').

(2) Arithmetic operations were essentially associated with school uses ('To find the answer to the math problem.').

(3) Measuring activities were mostly associated to outside-school uses ('To know the height of the person, to see if they have already grown.').

On the whole, children in both groups tended to give school-related uses to numbers and to sums in particular, whereas they tended to give outside-school uses to measurement.

To explain this result, it seems necessary to look at the mathematical activities the participants perform both in and out of school contexts, particularly in their living context. It is possible that the children in this study consider the activity of counting as a school-context activity. This is because in Brazil, mathematics textbooks directed to the first years of elementary school tend to favour the solution of arithmetic operations, either alone or in the solution of word problems (Mandarino 2009). On the other hand, measuring activities are not often proposed at school, so they were not associated with school uses. The opposite, however, seems to occur in the family context, as observed by Spinillo and Cruz (2016). Through natural observations in two different living contexts - home and orphanage - the authors verified that situations requiring measurements were the most frequent ones, especially among children living with their families. The children often had to measure the length of objects (e.g., the height of a wardrobe) or the distance between them (e.g., between the wardrobe and the bed), whereas arithmetic operations were performed mainly when doing homework. This was the case in both the family home and orphanage contexts. This possible explanation needs to be investigated further in future research through systematic observations of the school and living contexts of children from different social backgrounds. 


\subsection{Study 2}

The aim of Study 2 was to examine how children assign meaning to numbers. The participants were 40 children, 20 from a low-income background and 20 from a middle-class background. Each child was shown a number on a card, and asked to say what that number meant, choosing one of three alternatives presented orally. The multiple choice task consisted of 12 trials, and the alternatives referred to meanings assigned to numbers in everyday life, for example: 'Do you think this number (child is shown a card with the number 6) is (a) the age of a person, (b) a car number plate or (c) the number of books in a library?' and 'Do you think this number (child is shown a card with the number 401) is (a) the number of pills someone took in one day, (b) the number of a flat or (c) someone's age?'

In order to understand better the child's way of thinking, when the correct answer was chosen, ${ }^{3}$ the examiner asked the child why that number could not correspond to one of the other two alternatives (that is, the incorrect ones). The answers were audio-recorded and classified as vague or as precise, as exemplified below:

Do you think this number (shows a card with the number 82) is (a) the number of cars in someone's garage, (b) someone's age or (c) someone's telephone number?

Vague justification:

Child: It is someone's age.

Examiner: And why can it not be, for instance, someone's phone number?

Child: Because it can't.

Examiner: But why not?

Child: It just can't.

Examiner: Then explain to me why it cannot be.

Child: Because it's impossible.

Precise justification:

Child: It is someone's age.

Examiner: And why can it not be, for instance, someone's phone number?

Child: Because a phone number is a very long number. It has got many numbers. 82 only has two numbers, it is too short to be someone's phone number.

Do you think this number (shows card with the number 5900) is (a) the total number of pages in a comic book, (b) the amount of money someone has in the bank or (c) the number of floors in a building?

\footnotetext{
${ }^{3}$ The order in which the correct alternative was presented was randomized, so that in the first four trials the correct answer was presented as the first alternative, in the following four trials as a second alternative and in next four trials as the third.
} 
Table 35.2 Percentage of the types of justifications given to the correct answers per group

\begin{tabular}{l|l|l}
\hline & Low income $(n=157)$ & Middle class $(n=163)$ \\
\hline Vague justification & 62.4 & 28.2 \\
\hline Precise justification & 37.6 & 71.8 \\
\hline
\end{tabular}

Vague justification:

Child: An amount of money.

Examiner: And why could it not be the number of pages in a comic book?

Child: Because it cannot. This is money. I know it.

Examiner: And how do you know this? Can you explain it to me?

Child: I just know it.

Precise justification:

Child: The amount of money in a bank.

Examiner: And why could it not be the number of pages in a comic book?

Child: No. Comic books are not like this. It would be too many pages and no child would read a comic book with so many pages.

The percentage of correct responses did not vary between the two groups (Low income: $65.4 \%$ and Middle class: $67.9 \%$ ), but the types of justifications varied (see Table 35.2).

As shown in Table 35.2, the results differ between groups due to the percentage of vague justifications being significantly higher among low-income children than the percentage of precise justifications (Friedman test: $X=17.316, p=0.026$ ). The opposite is observed among middle-class children (Friedman test: $X=29.746$, $p=0.000)$. Also, vague justifications occurred more often among low-income (Mann-Whitney $U$ test: $U=-2.919, p=0.004$ ) than among middle-class children, whereas precise justifications were more frequently observed among the middle-class children (Mann-Whitney $U$ test: $U=-3.163, p=0.002$ ).

Thus, it is possible to say that children from different social backgrounds are able to successfully identify the different meanings assigned to numbers by society. The meanings assigned to numbers that were explored in this study were essentially number as a quantity of elements (number as cardinal, e.g., the number of books in a library) and as an identity (number as a nominal, e.g., a car number plate or a phone number). It would be interesting to investigate whether the two groups of children would differ in relation to the other different meanings that numbers may have in daily life beyond those examined in this study. For example, number as an ordinal (an athlete's position in relation to other athletes in a competition) and number as a measure (different dimensions such as length, volume, etc.).

However, the groups of children who participated in this study differ in their ability to express the foundations that underlie their judgments, since middle-class children can provide more precise justifications than lower-income children. A possible explanation for this result is given below. 


\subsection{General Discussion and Conclusions}

Taken together, the results from both studies show that there are some similarities and some differences between children from different social backgrounds with regard to the uses and meanings attributed to numbers in everyday life.

The first similarity is that children in both groups were able to identify the different meanings attributed to numbers in society. Regardless of their social background, they tended to attribute school uses to numbers and sums in particular, and to give outside-school uses to measurement. Also, although somewhat infrequent, there were children in both groups who associated mathematical knowledge with intellectual gains.

However, the groups also differ in some respects. Whereas low-income children tended to assign school uses to numbers, operations and the activity of measuring, middle-class children tended to attribute both school and extra-curricular uses to numbers. This suggests that middle-class children perceive a greater diversity of uses for numbers than low-income children, for whom numbers are mainly associated with the school context. It is important to mention that the uses related to professional activities are more frequently given by low-income children, who associated mathematical knowledge with work and subsistence.

Another aspect to be stressed is a child's ability to explain the bases that guide their judgments when they attribute meaning to numbers. The most remarkable difference between the groups is that middle-class children provided more accurate justifications than low-income children. This result can be explained in the light of Vergnaud's theory $(1983,1997)$, specifically in relation to what he calls 'theorems in action', which can be briefly defined as a non-explicit knowledge. Therefore, one can assume that low-income children have knowledge in action that allows them to appropriately assign different meanings to numbers. They are not, however, able to verbally state the basis of their judgments. On the other hand, middle-class children have a propositional knowledge that allows them to assign different meanings to numbers, as well as to verbally express the way they think, that is, explain the bases of their judgments. A possible explanation for this is that middle-class children are more used to giving explanations about the bases of their judgments than low-income children. However, it is necessary to be cautious when interpreting such data since, while insightful, the results derived from the reported studies are not definitive and other explanatory alternative hypotheses need to be considered in future research.

While the concept of number seems to be related to logical development, following a similar path independent of social environment (see Piaget's (1965) ideas about conservation of quantity and class inclusion, for instance), number sense seems to be a type of knowledge subject to greater variability, being dependent on the social experiences that individuals have with numbers in their everyday life. One may say that number sense is not the same for all: In other words, it is not equally distributed in society. This possibility needs to be further explored in future research with regard to number sense. However, based on results obtained in 
previous studies, such as those conducted by Nunes et al. (1993) and Saxe (1991), it is possible to assume that children acquire their mathematical knowledge from the interplay of activities they perform at home, at school and on the streets.

Teachers and researchers need to be fully aware of this fact. Teachers need to take it into account in school settings, especially during the early years of elementary school. Researchers should consider the relevance of using a variety of methodological recourses and investigative contexts when examining number sense in children. Different investigative contexts allow us to explore different aspects of number sense and to go beyond. For instance, future research could investigate, at least partially, where number sense comes from and use natural observations to look at the mathematical activities that children perform at home. Comparisons between children from different social backgrounds and also from different home environments, such as family and orphanage, could be of great importance, as the partial results of a recent exploratory study indicate (Spinillo and Cruz 2016). Such studies can help to identify and describe the mathematical activities performed by children in their home context, a context that has been little investigated with relation to mathematical knowledge.

\section{References}

Blevins-Knabe, B., \& Musun-Miller, L. (1996). Number use at home by children and their parents and its relationship to early mathematical performance. Early Development and Parenting, 5, $35-45$.

Brocardo, J., \& Serrazina, L. (2008). O sentido do número no currículo de matemática. In J. Brocardo, L. Serrazina, \& I. Rocha (Eds.), O sentido do número: Reflexões que entrecruzam teoria e prática (pp. 97-115). Lisboa: Escolar Editora.

Carraher, T. N., Carraher, D. W., \& Schliemann, A. D. (1985). Mathematics in the streets and in schools. British Journal of Developmental Psychology, 3, 21-29.

Cebola, G. (2007). Do número ao sentido de número. In J. P. Ponte, C. Costa, A. I. Rosendo, E. Maia, N. Figueiredo, \& A. F. Dionísio (Eds.), Atividades de investigação na aprendizagem da matemática e na formação de professores (pp. 223-239). Lisboa: Secção de Educação Matemática da Sociedade Portuguesa de Ciências da Educação.

Clements, D. H., \& Sarama, J. (2007). Effects of a preschool mathematics curriculum: Summative research on the building blocks project. Journal for Research in Mathematics Education, 38, $136-163$.

Gainsburg, J. (2005). School mathematics in work and life: What we know and how we can learn more. Technology in Society, 27, 1-22.

Godino, J. D., Font, V., Konic, P., \& Wilhem, M. R. (2009). El sentido numérico como articulatión flexible de los significados parciales de los números. In J. M. Cardeñoso \& M. Peñas (Eds.), Investigación en el aula de matemáticas. Sentido numérico (pp. 117-184). Granada: SAEM.

Greenes, C., Schulman, L., \& Spungin, R. (1993). Developing sense about numbers. Arithmetic Teacher, 40(5), 279-284.

Greeno, J. G. (1991). Number sense as situated knowing in a conceptual domain. Journal of Research in Mathematics Education, 23(3), 170-218. 
Jordan, N. C., Glutting, J., \& Ramineni, C. (2009). The importance of number sense to mathematics achievement in first and third grades. Learning and Individual Differences, 20(2), 82-88.

Mandarino, M. C. F. (2009). Que conteúdos da matemática escolar professores dos anos iniciais do ensino fundamental priorizam? In G. Guimarães \& R. Borba (Eds.), Reflexões sobre o Ensino de Matemática nos Anos Iniciais de Escolarização (pp. 101-118). Recife: SBEM.

McIntosh, A., Reys, B. J., \& Reys, R. E. (1992). A proposed framework for examining basic number sense. For the Learning of Mathematics, 12(3), 2-8.

MEC/SEF. (1997). Parâmetros Curriculares Nacionais, Matemática (Vol. 3). Brasília, Brasil: Secretaria de Educação Fundamental.

National Council of Teachers of Mathematics. (1989). The principles and standards for school mathematics. Reston, VA: NCTM.

Nunes, T., \& Bryant, P. (1996). Children doing mathematics. Oxford: Wiley-Blackwell.

Nunes, T., Schliemann, A. D., \& Carraher, D. W. (1993). Street mathematics and school mathematics. Cambridge: Cambridge University Press.

Piaget, J. (1965). The child's conception of number. New York: Norton.

Reys, B. J. (1989). Conference on number sense: Reflexions. In J. T. Sowder \& B. P. Schapelle (Eds.), Establishing foundations for research on number sense and related topics: Report of a conference (pp. 70-73). San Diego: Diego State University Center for Research in Mathematics and Science Education.

Ribeiro, L. M., \& Spinillo, A. G. (2006). Preschool children's number sense. In J. Novotná, H. Moraová, M. Krátiká, \& N. Stehliková (Eds.), Proceedings of the 30th Conference of the International Group for the Psychology of Mathematics Education (Vol. 1, p. 417). Prague, Czech Republic: PME.

Saxe, G. B. (1991). Culture and cognitive development: Studies in mathematical understanding. New Jersey: Lawrence Erlbaum Associates.

Siegler, R. S. (2009). Improving the numerical understanding of children from low-income families. Child Development Perspectives, 3, 118-124.

Spinillo, A. G. (2006). O sentido de número e sua importância na educação matemática. In M. R. F. de Brito (Ed.), Soluções de problemas e a matemática escolar (pp. 83-111). Campinas: Alínea.

Spinillo, A. G. (2011). Number sense in children: Understanding number as an operator when adding and subtracting. In B. Ubuz (Ed.), Proceedings of the 35th Conference of the International Group for the Psychology of Mathematics Education (Vol. 4, pp. 201-209). Ankara, Turkey: PME.

Spinillo, A. G., \& Batista, R. M. F. (2009). A sense of measurement: What do children know about the invariant principles of different types of measurement? In M. Tzekaki, M. Kaldrimidou, \& H. Sakonidis (Eds.), Proceedings of the 33rd Conference of the International Group for the Psychology of Mathematics Education (Vol. 5, pp. 161-168). Thessaloniki, Greece: PME.

Spinillo, A. G., \& Cruz, M. S. S. (2016). Number sense in children from different living contexts. In C. Csikos, A. Rausch, \& J. Szitànyi (Eds.), Proceedings of the 40th Conference of the International Group for the Psychology of Mathematics Education (Vol. 1, p. 240). Szeged, Hungary: PME.

Vergnaud, G. (1983). Multiplicative structures. In R. Lesh \& M. Landau (Eds.), Acquisition of mathematics: Concepts and processes (pp. 127-174). London: Academic Press. 
Vergnaud, G. (1997). The nature of mathematics concepts. In T. Nunes \& P. Bryant (Eds.), Learning and teaching mathematics: An international perspective (pp. 5-28). Sussex: Psychology Press.

Yang, D.-C. (2003). Teaching and learning number sense-An intervention study of fifth grade students in Taiwan. International Journal of Science and Mathematics Education, 1, 115-134.

Yang, D.-C., Hsu, C.-J., \& Huang, M.-C. (2004). A study of teaching and learning number sense for sixth grade students in Taiwan. International Journal of Science and Mathematics Education, 2, 407-430.

Open Access This chapter is licensed under the terms of the Creative Commons Attribution 4.0 International License (http://creativecommons.org/licenses/by/4.0/), which permits use, sharing, adaptation, distribution and reproduction in any medium or format, as long as you give appropriate credit to the original author(s) and the source, provide a link to the Creative Commons license and indicate if changes were made.

The images or other third party material in this chapter are included in the chapter's Creative Commons license, unless indicated otherwise in a credit line to the material. If material is not included in the chapter's Creative Commons license and your intended use is not permitted by statutory regulation or exceeds the permitted use, you will need to obtain permission directly from the copyright holder.

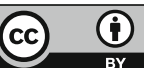

